UNIVERSIDADE DE BRASILIA - UnB

FACULDADE DE CIÊNCIAS DA SAÚDE - FS

NÚCLEO DE ESTUDOS EM EDUCAÇÃO E PROMOÇÃO DA SAÚDE - NESPROM PÓS-GRADUAÇÃO LATO SENSU EM EDUCAÇÃO E PROMOÇÃO DA SAÚDE

\title{
"VOCÊ TAMBÉM É RESPONSÁVEL POR SUA SAÚDE!" - comparação entre informações concedidas para população e pesquisas correlatas
}


"VOCÊ TAMBÉM É RESPONSÁVEL POR SUA SAÚDE!" - comparação entre informações concedidas para população e pesquisas correlatas.

Artigo apresentado ao Núcleo de Estudos em Educação e Promoção da Saúde, para obtenção do título de especialista em Educação e Promoção da Saúde, da Universidade de Brasília, Faculdade de Ciências da Saúde.

Brasília, 2010 
Ao meu

esposo Ericson, companheiro em todos os momentos de minha vida, um dos meus maiores incentivadores. Ao meu filho Rafael, razão da minha vida. 


\section{AGRADECIMENTOS}

A Deus, por me proporcionar sabedoria e direcionar meus passos.

Aos meus pais, Otone e Maria, pelo amor, dedicação e ensinamentos.

Ao meu esposo e ao meu filho, por entenderem a ausência durante o tempo que me dediquei a este trabalho.

À Iraci pelo privilégio da orientação e incentivo recebido. Obrigada pelo tempo dispensado e por entender as minhas dificuldades em momento tão conturbado de minha vida pessoal.

Aos pacientes, a quem pude oferecer a minha atenção e cuidados, muitas vezes em momentos de sofrimento e de fragilidade.

A todos os profissionais de enfermagem, pela convivência durante a trajetória profissional, sempre proporcionando reflexão para o aprimoramento das práticas do cuidado. 
CARNEIRO, Nadia Gislene Gomes. GUIMARÃES, Iraci Gonçalves. "Você também é responsável por sua saúde!" - comparação entre informações concedidas para população e pesquisas correlatas. Trabalho de Conclusão do Curso de Pós-graduação lato sensu em Educação e Promoção da Saúde, Núcleo de Estudos em Educação e Promoção da Saúde, Faculdade de Ciências da Saúde, Universidade de Brasília, Brasília, DF, 2010.

\section{RESUMO}

Segundo dados do IBGE de 2002, o número de habitantes com 60 anos e mais tem aumentado significativamente em comparação com o restante da população do país. Existe previsão de que em 2025 o Brasil seja o sexto país com maior número de idosos no ranking mundial, o que nos fará a conviver com uma população cada vez mais envelhecida, sendo necessárias políticas sociais e de saúde voltadas para esta população, as quais proporcionem qualidade de vida. Para a OMS (1994), a qualidade de vida é definida como a percepção do indivíduo sobre a sua posição na vida, no contexto da cultura e dos sistemas de valores nos quais ele vive, e em relação a seus objetivos, expectativas, padrões e preocupações. Pensando nisto, este trabalho baseia-se em uma pesquisa qualitativa, definida como uma revisão bibliográfica sobre qualidade de vida para o idoso, com o objetivo de analisar e fundamentar as informações básicas transmitidas sobre qualidade de vida no envelhecimento por um folder fornecido pelo Governo do Distrito Federal e os registros mostrados pela literatura científica sobre o envelhecimento e qualidade de vida no Brasil. Foi utilizado o banco de dados do Scielo (Scientific Eletronic Library Online), através de pesquisa de artigos científicos relacionados ao tema. Dos artigos encontrados, foram selecionados artigos relativos à educação e promoção da saúde do idoso, voltados para a comparação aos tópicos discutidos no folder utilizado para o desenvolvimento deste artigo, em idioma português, totalizando 10 artigos. Como resultados, dentre os assuntos retratados no folder, os que encontram fundamentação da literatura para a promoção da qualidade de vida ao idoso, incluem a prática de exercícios físicos, participação em grupos de convivência, cuidados com alimentação, prevenção de acidentes e procura do serviço de saúde para vacinação. Verifica-se que o folder utilizado para o desenvolvimento deste trabalho traz inúmeras informações pertinentes no que diz respeito à promoção e educação da saúde de idoso, o que pode ser confirmado pelos estudos científicos disponíveis. Algumas adaptações são sugeridas, visando um melhor aproveitamento das informações e adesão às propostas de ação educativas, como por 
exemplo, utilizar-se de menos textos e incluir mais figuras ilustrativas, uma vez que a grande maioria da nossa população-alvo, ou tem nível de escolaridade baixo, ou tem problemas de acuidade visual. Nós, profissionais de saúde, nos vemos desafiados a corresponder qualitativamente às demandas dos idosos, que com o aumento da longevidade, requer políticas de saúde voltadas à qualidade de vida através de programas voltados para esta população com ênfase na promoção e educação em saúde.

Palavras-chave: Idoso; Qualidade de Vida; Educação em Saúde; Promoção da Saúde. 
Carneiro, Nadia Gislene Gomes; Guimarães, Iraci Gonçalves. "You also are responsible for your health" - comparison between information sent to population and similar researches. Final Result for Conclude the After-graduation Course lato sensu in Education and Promotion of the Health, Nucleus of Studies in Education and Promotion of the Health, College of Sciences of the Health, University of Brasilia, Brasilia, DF, 2010.

\begin{abstract}
According to data of the IBGE of 2002, the number of inhabitants aged 60 years or more has increased significantly compared to the rest of the population of the country. There is a current elderly population survey that indicates Brazil as the sixth country with more old people aged in all over the world in 2025. Thus, that will make was to deal with an increasing elderly population in Brazil, time after time. So, the increase in the elderly population has propitiated debate on social policies for the health and care of a growing number of the elderly population in Brazil, in order to improve their well-being. For the World Health Organization - WHO (1994), the quality of life is defined as the perception of the human being in his position in the life, in the context of the culture and in the systems of values in which he lives, and in relation to his objectives, expectations, standards and concerns. Thinking about this, this survey is based on a qualitative research, defined as a bibliographical revision on quality of life for the elderly population, with the objective to analyze and to evidence the transmitted basic information on quality of life for the elderly population in a folder supplied for the Government of the Distrito Federal, Brazil. This research contains scientific articles from the data base of the Scientific Electronic Library Online, Scielo, of related scientific articles to the subject. From the articles that we found in the data base of Scielo, only the relatives on health on education and promotion for the elderly population were selected to compare with the topics of the folder supplied by the government of Distrito Federal, Brazil, in portuguese language, totalizing 10 articles. As results, amongst the subjects reported in the government folder are: practice of physical exercise, taking part in happy hour groups, care with feeding, prevention of accident and the demand for public health vaccination are the ones that find recital of literature for the promotion of the quality of life for the elderly population. On the other hand, it was not found literature articles that deal with the sexuality in the third age or exercise that keep the brain active. It was verified that the folder used for the development of this research shows an innumerable pertinent information
\end{abstract}


that respect the promotion and education for the health of the elderly population, what can be confirmed by the available scientific studies. Some adaptations are suggested, aiming at a better exploitation of the information and adhesion to the proposals of educative action, as for example, the non use of text, and the inclusion of more illustrative figures, considering that the great majority of our population-target has low level of escolarity, or visual problems. We, health professionals, feel dare to pay attention to the growing demands of the elderly population, with the growing numbers of oldsters that require health polices to the quality of life through programs toward this population with emphasis in the promotion and education in health.

Keywords: Aged; Quality of Life; Education in Health; Promotion of the Health. 


\section{LISTA DE TABELAS}

Tabela 1 - Descrição dos textos selecionados para revisão bibliográfica

Tabela 2 - Relação dos tópicos do folder e os artigos científicos selecionados p.23

Tabela 3 - Comparação entre o folder e a literatura científica em artigos $\quad$ p.28 brasileiros 


\section{LISTA DE ABREVIATURAS}

CNS Conselho Nacional de Saúde

IBGE Instituto Brasileiro de Geografia e Estatística

FS Faculdade de Ciências da Saúde

MS Ministério da Saúde

NESPROM Núcleo de Estudos em Promoção e Educação em Saúde

OMS Organização Mundial de Saúde

SCIELO Scientific Eletronic Library Online

UnB Universidade de Brasília

OMS/WHO Organização Mundial de Saúde 


\section{SUMÁRIO}

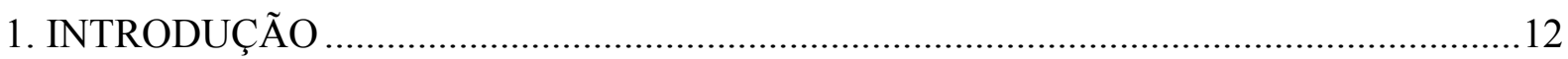

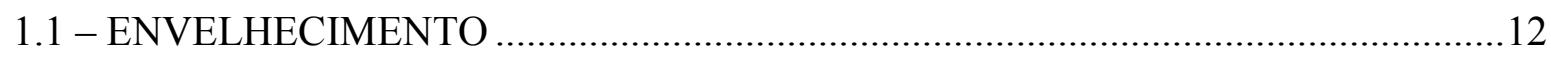

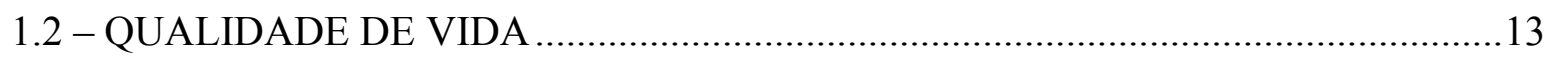

1.3 - PROMOÇÃO DA SAÚDE E EDUCAÇÃO EM SAÚDE ………………………….......14

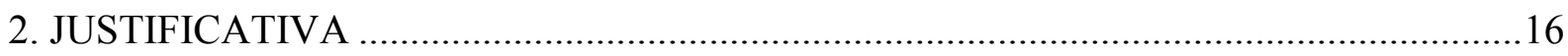

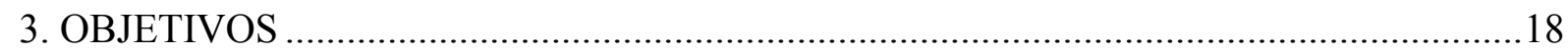

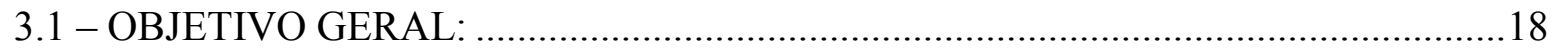

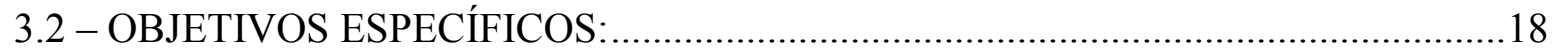

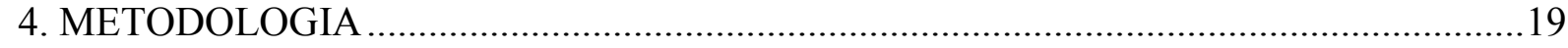

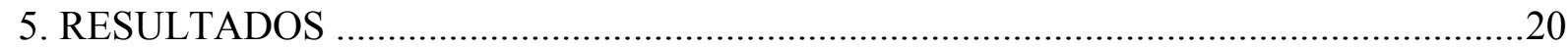

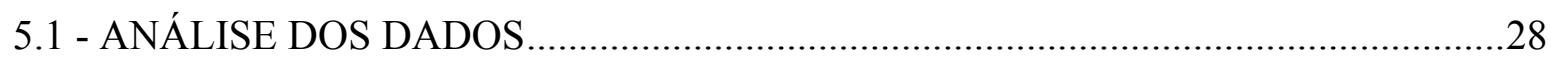

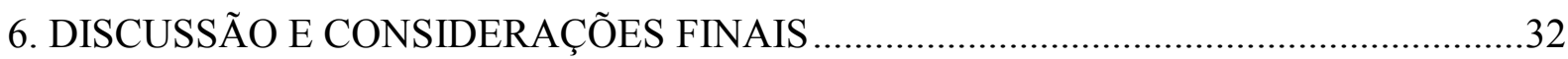

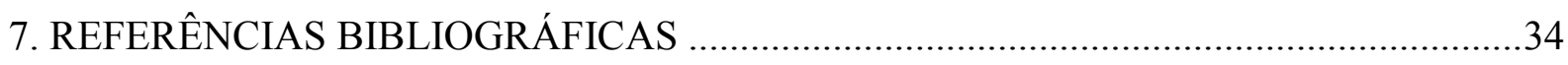

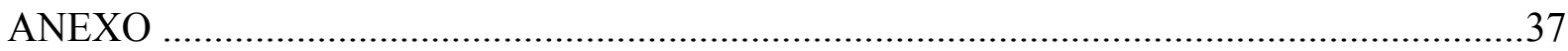




\section{INTRODUÇÃO}

De acordo com o Instituto Brasileiro de Geografia e Estatística (2002), no período de 1991 a 2000, o número de habitantes com sessenta anos e mais aumentou 2,5 vezes (35\%) em comparação com o restante da população do país (14\%). No Brasil, estima-se que em 2025 poderão existir 33,8 milhões de idosos, colocando o país no sexto lugar do ranking mundial (OMS, 2002, apud Guimarães, 2005).

Segundo a Organização Mundial de Saúde (OMS/ WHO - World Health Organization, 2001, apud Guimarães, 2005) em 2000 havia em todo o mundo 600 milhões de pessoas com 60 anos ou mais, estimando-se em 1,2 bilhões o número a ser alcançado em 2025, portanto, o envelhecimento é um fenômeno global (Tavares et al., 2007).

No Brasil, este fenômeno está relacionado à melhoria do acesso aos serviços de saúde pública, à consolidação de um sistema universal de saúde pública, à prevenção de doenças infecto-contagiosas, aos avanços tecnológicos da medicina, ao aumento do acesso à rede pública de saneamento, à melhoria dos níveis de escolaridade, os quais contribuíram para o aumento da expectativa de vida (Dias Jr, 2006, apud Castro, 2009).

\section{1 - ENVELHECIMENTO}

Segundo Ponte (1996), o envelhecimento é um processo irreversível, que ocorre durante a vida, do nascimento à morte, sendo acompanhado pelo declínio das funções biológicas da maior parte dos órgãos. Para Pereira et al. (2004), o envelhecer depende significativamente do estilo de vida e não é uniforme, uma vez que o organismo envelhece como um todo, ao passo que seus órgãos, tecidos, células e estruturas subcelulares apresentam desgaste diferenciado com o passar da idade.

O envelhecimento não parece ser definido pela idade de uma pessoa, mas sim pelos efeitos que essa idade teria causado no organismo, sendo a velhice percebida como fenômeno natural e social que se desenrola sobre o ser humano, único, indivisível, que, na sua totalidade existencial, defronta-se com problemas e limitações biológica, econômica e sociocultural, que singularizam seu processo de envelhecimento (Groisman, 2002, apud Melo, 2009).

Diante da realidade das transformações demográficas iniciadas no último século, que nos fazem conviver com uma população cada vez mais envelhecida, evidencia-se a 
necessidade e a importância de garantir aos idosos não só uma sobrevida maior, mas necessariamente qualidade de vida, o que requer preocupação voltada para o envelhecimento saudável, o que nos faz pensar em aspectos preventivos em relação ao envelhecimento, uma vez que é um processo crônico-degenerativo tempo-dependente, pelo qual cada vez mais pessoas estarão fadadas a passar (Arking, 1998, apud Rodrigues 2008).

Por fim, o idoso para Camarano (2002, apud Guimarães, 2005) é aquele que tem a idade limite e superior a 60 anos, e que apesar de toda a dificuldade em estabelecer o que é ser idoso, o critério idade parece ser o mais aceito, em diversos trabalhos publicados sobre envelhecimento.

\section{$1.2-Q U A L I D A D E D E V I D A$}

Para a Organização Mundial de Saúde (OMS/WHO - World Health Organization, 1994, apud Melo, 2009) a qualidade de vida pode ser definida como "a percepção do indivíduo sobre a sua posição na vida, no contexto da cultura e dos sistemas de valores nos quais ele vive, e em relação a seus objetivos, expectativas, padrões e preocupações" (p. 3). Nessa definição, incluem-se seis domínios principais: saúde física, estado psicológico, níveis de independência, relacionamento social, características ambientais e padrão espiritual (Melo, 2009).

Santos (2002, apud Vecchia, 2005) define qualidade de vida considerando a autoestima, o bem-estar pessoal, aspectos como a capacidade funcional, o nível socioeconômico, o estado emocional, a interação social, a atividade intelectual, o autocuidado, o suporte familiar, o próprio estado de saúde, os valores culturais, éticos e a religiosidade.

Para Vecchia et al. (2005) o conceito de qualidade de vida varia de autor para autor, além de ser um conceito subjetivo dependente do nível sociocultural, da faixa etária e das aspirações pessoais do indivíduo.

Queiroz (2004, apud Melo, 2009) entende qualidade de vida como uma expressão que se reveste de grande complexidade, dada a subjetividade que representa para cada pessoa ou grupo social e que apesar de não haver um consenso quanto à definição de qualidade de vida, em um nível abstrato, alguns autores, como Fleck (1999, apud Melo, 2009), tem considerado que existe um conceito "universal cultural" de qualidade de vida, isto é, independente da nação, cultura ou época, é importante que as pessoas se sintam bem psicologicamente, tenham boas condições físicas e sintam-se socialmente integradas e funcionalmente competentes. 
Nahas (2001), a define como a condição humana resultante de um conjunto de parâmetros individuais e sócio-ambientais, que pode ou não ser modificado, caracterizando as condições em que vive o ser humano.

\section{3 - PROMOÇÃO DA SAÚDE E EDUCAÇÃO EM SAÚDE}

A Carta de Ottawa ${ }^{1}$, decorrente da I Conferência Internacional sobre Promoção da Saúde (1986) definiu a promoção da saúde como:

“o processo de capacitação da comunidade para atuar na melhoria da sua qualidade de vida e saúde, incluindo uma maior participação no controle deste processo e subjacente a este conceito, o documento assume que a saúde é o maior recurso para o desenvolvimento social, econômico e pessoal, assim como uma importante dimensão da qualidade de vida".

Na visão de Buss (2000, apud Melo, 2009), a promoção da saúde caracteriza-se pelo entendimento que a saúde é produto de um amplo espectro de fatores relacionados com a qualidade de vida, incluindo um padrão adequado de alimentação e nutrição, e de habitação e saneamento; boas condições de trabalho; oportunidades de educação ao longo da vida; ambiente físico limpo; apoio social para famílias e indivíduos; estilo de vida responsável; e um espectro adequado de cuidados de saúde.

A ação educativa em saúde é um processo dinâmico que tem como objetivo a capacitação dos indivíduos em busca de melhoria das condições de saúde. Neste processo, porém, a população tem a opção de aceitar ou rejeitar as novas informações, podendo também, adotar ou não novos comportamentos frente aos problemas de saúde. Não basta seguir normas recomendadas de como se ter mais saúde e evitar doenças, e sim realizar a educação em saúde num processo que estimule o diálogo, a reflexão, o questionamento, a ação partilhada e principalmente valorização do contexto em que está inserido o sujeito objeto da ação.

\footnotetext{
${ }^{1}$ A Carta de Ottawa foi elaborada e adotada por uma conferência internacional, organizada conjuntamente pela Organização Mundial de Saúde (OMS), o Ministério de Saúde e Bem-Estar Social do Canadá e a Associação Canadense de Saúde Pública, onde participaram 200 delegados de 38 países, os quais se reuniram para trocar experiências e conhecimentos relativos à promoção da saúde, tendo ocorrido de 17 a 21 de novembro de 1986 (Ministério da Saúde, As Cartas da Promoção da Saúde, 2002).
} 
Para Ramos (2003), no Brasil, o desafio para este século é oferecer qualidade de vida para uma população com mais de 32 milhões de idosos, na sua maioria de nível sócioeconômico e educacional baixo e com alta prevalência de doenças crônicas e incapacitantes. Contudo, para atenção adequada ao idoso, pensando na complexidade e na magnitude de seus problemas funcionais, é imprescindível o desenvolvimento de políticas sociais e de saúde condizentes com as reais necessidades deste grupo populacional.

Torna-se necessário o desenvolvimento de ações de educação em saúde, com entendimento integral a respeito de saúde e de qualidade de vida, valorizando a história de vida da população, estimulando a autoconfiança e desenvolvendo atitudes e práticas de cidadania adequadas. Para a OMS (2001, apud Melo, 2009) os objetivos da educação em saúde são desenvolver nas pessoas o senso de responsabilidade pela sua própria saúde e pela saúde da comunidade a qual pertençam e a capacidade de participar da vida comunitária de uma maneira construtiva.

Educar o idoso para conhecer e acreditar em suas reais capacidades, desenvolver seus talentos, ensiná-lo a colocar o conhecimento a serviço de sua construção como sujeito, criar oportunidades para que aprenda a enfrentar obstáculos e preconceitos sociais, são ações que significam contribuir para promover a sua qualidade de vida e para o aprimoramento de sua cidadania (Cachione, 2003 apud Alencar 2008). 


\section{JUSTIFICATIVA}

Ações educativas podem contribuir para mudanças no estilo de vida, favorecendo o conhecimento, sendo, portanto, um dos meios para vencer os desafios impostos aos idosos pela idade e pela sua condição de saúde, propiciando, também, o aprendizado de novas formas de cuidar, ampliando as oportunidades para resgatar seu bem-estar físico e emocional.

Estas ações podem ser desenvolvidas de formas diversas, dentre elas, palestras, grupos interativos, oficinas, disponibilização de cartilhas, folders, veiculação de informações na imprensa. A preocupação que deve existir é contextualizar tais ações para os grupos que se deseja atingir. Na população idosa, por exemplo, as alterações fisiológicas (acuidade visual e auditiva), o nível sócio-econômico e de escolaridade, os fatores culturais e religiosos podem interferir no entendimento e adesão a determinadas ações.

Em minha atuação diária como enfermeira em Pronto-Socorro de um hospital público no Distrito Federal, deparei-me com uma demanda expressiva de idosos com doenças crônicas, os quais apresentam limitações importantes, incapacidades e dependência física. Diante desta realidade, comecei a me questionar sobre a qualidade de vida neste grupo, o que contribuiu para a reflexão acerca das ações de promoção e educação em saúde bem como da atuação dos profissionais de saúde.

A prevenção, o tratamento e o controle de doenças crônicas exigem mudanças de comportamento relacionadas ao estilo de vida de cada indivíduo, o que contribuirá para a qualidade de vida. Se não houver orientação adequada quanto ao tratamento ou o reconhecimento da importância das complicações que decorrem destas patologias, provavelmente a adesão ao tratamento pode ficar comprometida, o que resulta em internações e aumento de custos hospitalares. Desta forma, entendo como prioridade o desenvolvimento de ações que se tornem efetivas para este grupo específico, valorizando sempre sua individualidade e contextualizando todos os aspectos que permeiam a vida deste ser.

Frente à necessidade de uma perspectiva multidisciplinar completa e, assim como no atendimento infantil, a implementação de atendimentos complementares voltados ao idoso é de fundamental importância para o tratamento e acompanhamento deste grupo etário.

Além disso, diante da carência de profissionais qualificados para lidar com a população idosa, inclusive com o uso adequado de material didático de apoio, e, com os dados mostrados pela literatura científica sobre envelhecimento que geralmente enfatizam a perda e as limitações provenientes desta fase do desenvolvimento humano, pesquisas de revisão e de 
comparação de conteúdo científico são importantes no aprimoramento do atendimento ao idoso. 


\section{OBJETIVOS}

\section{1 - OBJETIVO GERAL:}

Comparar informações sobre ações de educação e promoção da saúde do idoso em um folder sobre qualidade de vida para idosos distribuído pelo governo distrital e os dados obtidos na literatura científica.

\section{2 - OBJETIVOS ESPECÍFICOS:}

- Conhecer os fatores que interferem na efetividade das ações do programa, relativas à qualidade de vida do idoso.

- Verificar a adequabilidade do folder diante das dificuldades do idoso e das políticas de ação pública do programa do idoso frente aos dados da literatura científica.

- Identificar as informações necessárias e as paradoxais listadas no folder, conforme parâmetros de qualidade de vida do público-alvo.

- Identificar se os itens elencados no folder são descritos no meio científico como fatores que contribuem para a qualidade de vida nos idosos. 


\section{METODOLOGIA}

Esta pesquisa é qualitativa, com aspectos exploratórios, pois visa uma análise global definida como uma revisão bibliográfica sobre qualidade de vida para o idoso, e consiste na análise e fundamentação das informações básicas transmitidas sobre qualidade de vida no envelhecimento por um folder (Anexo I) fornecido pelo Governo do Distrito Federal e os registros mostrados pela literatura científica sobre o envelhecimento e qualidade de vida no Brasil.

Conforme a resolução 196/96 do Conselho Nacional de Saúde (CNS, 1996) e pelos preceitos do Comitê de Ética da Faculdade de Ciências da Saúde, não foi necessário aprovação por não se tratar de trabalho científico que envolva o ser humano direta ou indiretamente.

Foi utilizado o banco de dados da biblioteca eletrônica Scielo (Scientific Eletronic Library Online), onde se realizou a busca de artigos científicos, inicialmente usou-se a palavra IDOSO, como primeira palavra-chave para filtragem de artigos; pois, a idéia é analisar artigos que mostrem o individuo idoso ou a população idosa participante e alvo de pesquisas, e não o processo de envelhecimento ou envelhecer Após esta primeira etapa, adicionou-se ao buscador a expressão QUALIDADE DE VIDA, refinando-se a pesquisa para artigos e pesquisas sobre idoso e qualidade de vida, no idioma português. Dos artigos encontrados, foram selecionados apenas os artigos relativos à educação e promoção da saúde do idoso, voltados para a comparação aos tópicos discutidos no folder utilizado para o desenvolvimento deste artigo. 


\section{RESULTADOS}

$\mathrm{Na}$ pesquisa de artigos foram encontrados 442 com referência a palavra IDOSO. Refinando-se a pesquisa, foram encontrados 59 artigos sobre qualidade de vida, sendo destes 54 escritos em idioma português, pois qualidade de vida é um conceito complexo e dependente de contexto, portanto apenas os artigos em português, produzidos no Brasil foram analisados. Ao final, foram selecionados 10 artigos para o desenvolvimento da revisão bibliográfica, tendo como critérios de inclusão ter relação com os tópicos apresentados no folder escolhido sobre saúde do idoso e serem relativos à educação e promoção da saúde do idoso.

O resultado da pesquisa está descrito nas tabelas a seguir, de modo que os artigos selecionados na revisão bibliográfica estão listados na tabela 1 e a associação de tais textos com os tópicos do folder está na tabela 2. A tabela 3 traz a análise dos dados. 


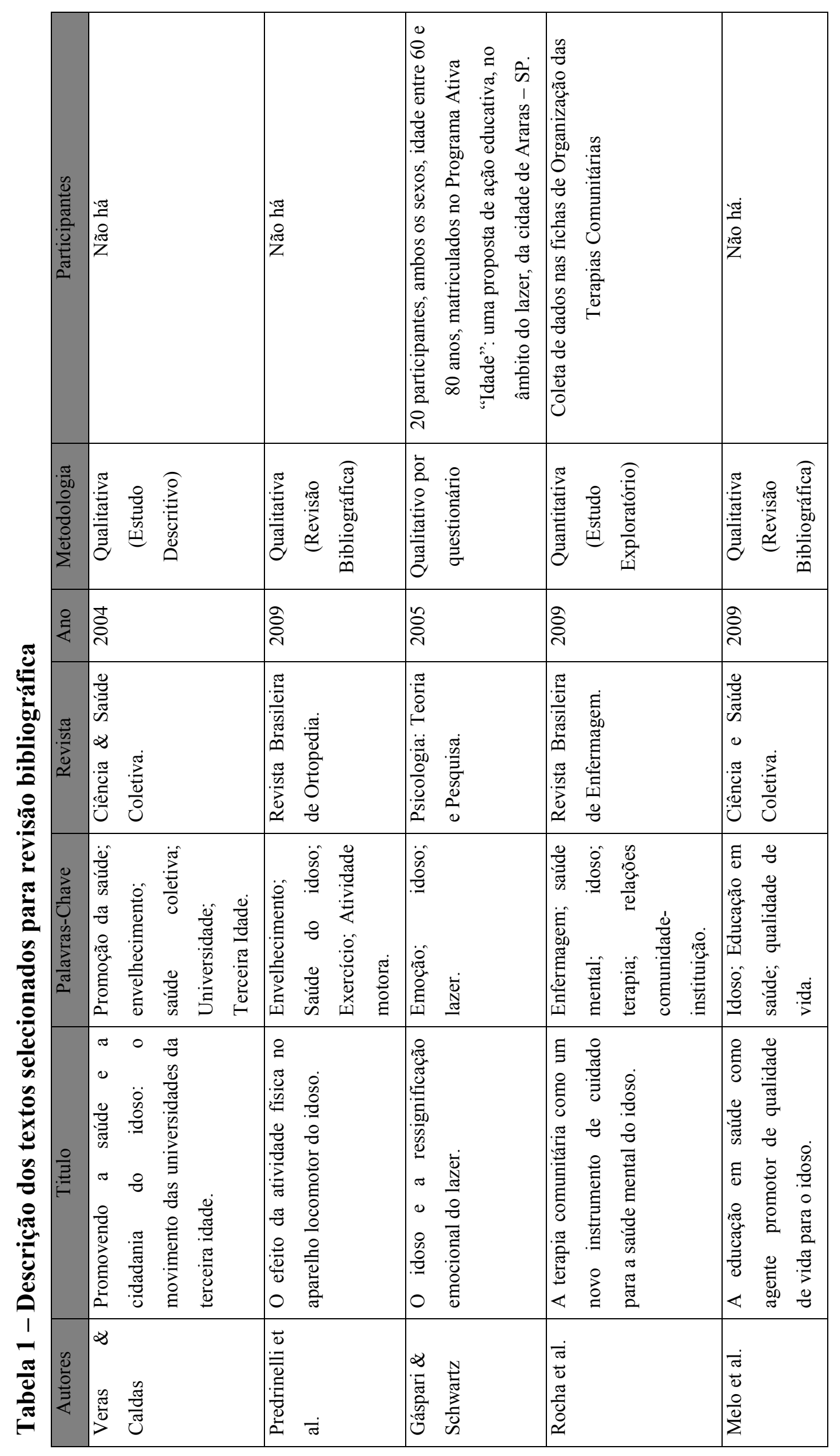




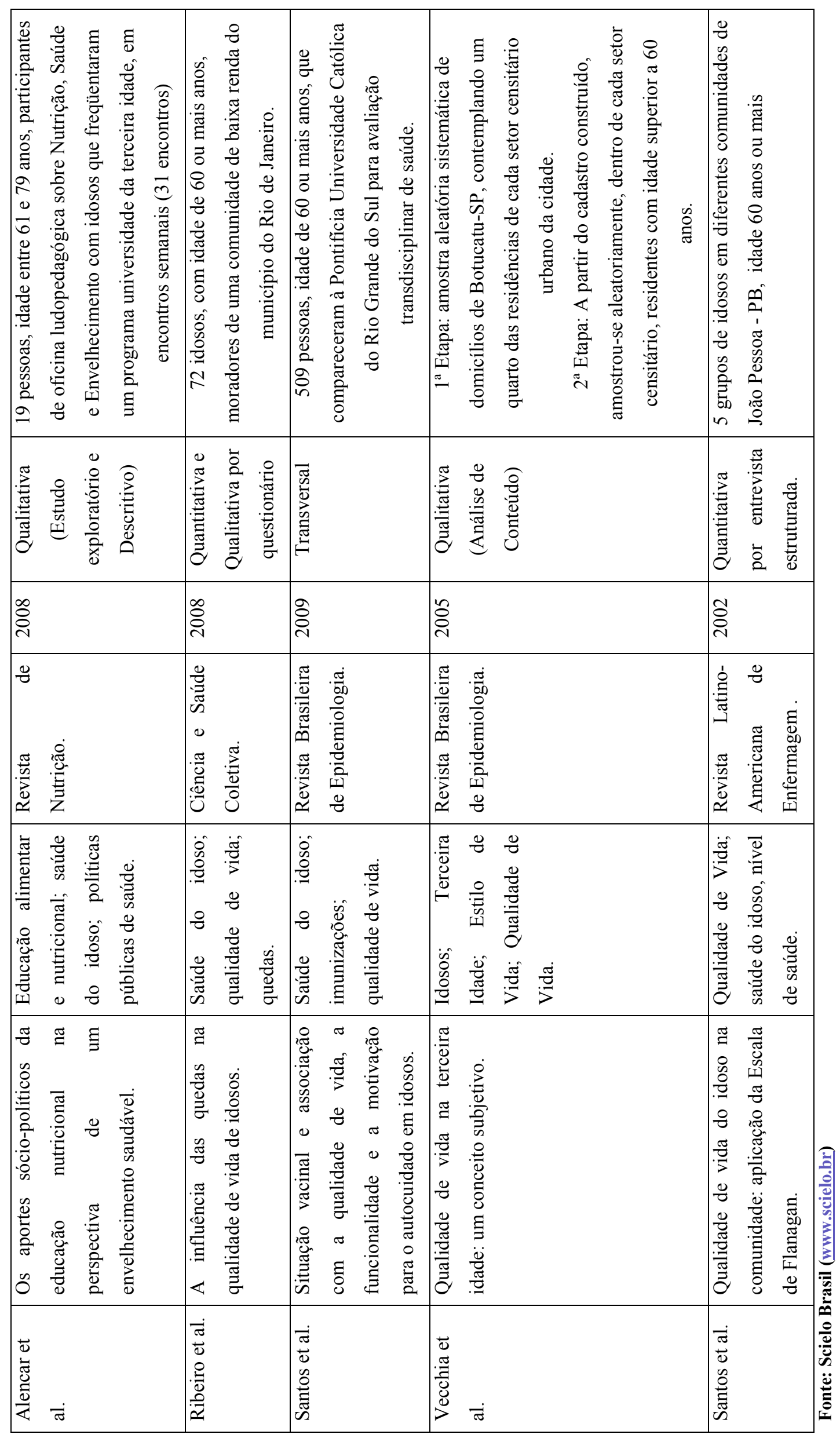




\section{Tabela 2 - Relação dos tópicos ${ }^{2}$ do folder e os artigos científicos selecionados}

\section{TÓPICO 1 do folder : Exercite o cérebro e mantenha-se atualizado!}

Artigo - Promovendo a saúde e a cidadania do idoso: o movimento das universidades da terceira idade (Veras \& Caldas, 2004).

$\mathrm{O}$ artigo descreve o movimento Universidades da Terceira Idade, um programa com experiência de dez anos, desenvolvido na Universidade do Estado do Rio de Janeiro, o qual objetiva contribuir para uma melhor compreensão da lógica de promoção da saúde do idoso e compartilhar com o público os marcos de um modelo de cuidado integral. Este programa tem propósito de rever os estereótipos e preconceitos com relação à velhice, promover a auto-estima e o resgate da cidadania, incentivar a autonomia, a independência, a autoexpressão e a reinserção social em busca de uma velhice bem-sucedida, contribuindo desta forma, para a promoção da saúde física, mental e social das pessoas idosas, lançando mão das possibilidades existentes nas universidades.

\section{TÓPICO 2 do folder: Exercite o corpo para não enferrujar!}

Artigo - O efeito da atividade física no aparelho locomotor do idoso (Predrinelli et al., 2009).

Este estudo é uma revisão bibliográfica acerca da atividade física para a população idosa, o qual objetivou explicar como a atividade física pode trazer benefícios ao aparelho musculoesquelético dos idosos e expor quais são os exercícios usualmente indicados para essa população. Os benefícios relatados incluem, melhora do equilíbrio corporal do indivíduo idoso, maior estabilidade na marcha, controle da dor, melhora da independência e da qualidade de vida, prevenção do risco de quedas, fortalecimento muscular, retardo ou reversão de massa óssea relacionada com a idade.

\footnotetext{
${ }^{2}$ Tópicos referentes ao folder distribuído aos idosos em atendimentos públicos no Distrito Federal.
} 


\section{TÓPICO 3 do folder: Exercite a alma e não se isole!}

Artigo - O idoso e a ressignificação emocional do lazer (Gáspari \& Schwartz, 2005).

Trata dos aspectos emocionais na percepção de idosos, durante vivências no lazer através de um estudo através da Técnica de Análise de Conteúdo, que teve como objetivo identificar alguns aspectos psicológicos e sociais presentes na percepção dos idosos. Os idosos reconheceram que ao participarem de um programa de educação educativa para sua idade aprendem várias coisas, sentem-se importantes, valorizados, incentivados, animados, fazem novas amizades, conhecem mais pessoas, divertem-se, distraem-se e melhoram a qualidade de vida. Outros aspectos importantes encontrados é o combate da depressão, da tristeza e evitar o isolamento. Além disso, os idosos experimentaram sentimentos de alegria e respeito mútuo, relatando que os problemas haviam ficado menores. Neste estudo, a concepção de qualidade de vida para os idosos é entendida nas expressões como vida melhor, viver unido, amar a si mesmo, viver com dignidade, ter tratamento médico especial, alimentação adequada, viver em harmonia, viver bem, ter saúde, paz, felicidade, tranqüilidade e disposição para trabalhar e lutar pela família, amar a Deus. Estas sensações percebidas pelos idosos, ao participarem do Programa, representam um forte indício de que tais experiências podem ser capazes de ressignificar, não apenas as vivências no âmbito do lazer, mas, proporcionar um novo dimensionamento em todos os aspectos da vida em geral.

Artigo - A terapia comunitária como um novo instrumento de cuidado para saúde mental do idoso (Rocha et al., 2009).

Descreve o papel da Terapia Comunitária como uma ferramenta de cuidados nos programas de inserção e apoio à saúde mental da população idosa. A Terapia Comunitária consiste em um espaço de acolhimento, escuta, reflexão e troca de experiências, para a partilha de sofrimentos e sabedoria de vida, criando uma teia de relação social entre os participantes, na busca de soluções para os conflitos pessoais e familiares. Beneficia as relações interpessoais, a formação de redes sociais solidárias e a utilização da cultura popular como subsídio para soluções de problemas vividos pela comunidade. O artigo trata de uma pesquisa exploratória com o objetivo de identificar o número de grupos de terapia comunitária com idosos em João Pessoa - PB, conhecer os principais temas apresentados pelos idosos e as estratégias utilizadas para o enfrentamento das dificuldades e revelar depoimentos relacionados à melhoria da qualidade de vida dos idosos, tendo como 
resultados que o problema mais freqüente nos idoso é o estresse, a estratégia de enfrentamento mais utilizada é a espiritualidade e que a Terapia Comunitária vem contribuindo para saúde mental do idoso.

\section{TÓPICO 4 do folder: Cuide de sua saúde e alimentação!}

Artigo - Os aportes sócio-políticos da educação nutricional na perspectiva de uma envelhecimento saudável (Alencar et al., 2008).

Analisa a contribuição da educação nutricional a partir de suas dimensões sócio-políticas que permeiam a promoção da saúde. Após o estudo foi possível elaborar uma reflexão sobre a educação gerontológica, com ênfase nas dimensões sócio-políticas da educação nutricional, capaz de permear hábitos alimentares e estilo de vida saudáveis no curso da vida, pressupondo que ações interdisciplinares que visam à preservação, à manutenção ou à promoção da capacidade funcional do cidadão idoso, são possibilidades na direção da busca da qualidade de vida dos que envelhecem.

\section{TOPICO 5 do folder : Brinque, beije e namore, mas use camisinha!}

Não foi encontrado artigo relacionado ao tópico.

\section{TOPICO 6 do folder : Evite acidentes!}

Artigo - A influência das quedas na qualidade de vida de idosos (Ribeiro et al., 2008).

Neste artigo foi realizado um estudo para analisar o efeito das quedas e suas conseqüências na qualidade de vida de idosos. As quedas são freqüentes entre os idosos e apresentam diversos impactos na vida de um idoso, que podem incluir morbidade importante, mortalidade, deterioração funcional, hospitalização, institucionalização e consumo de serviços sociais e de saúde. Além das conseqüências diretas da queda, os idosos restringem suas atividades devido a dores, incapacidades, medo de cair, atitudes protetoras, resultando desta forma, em conseqüências que alteram negativamente a qualidade de vida. As quedas podem ser evitadas com medidas preventivas adequadas, identificando-se causas e desenvolvendo-se métodos para reduzir suas ocorrências. 


\section{TOPICO 7 do folder : Procure o serviço de saúde! Vacine-se!}

Artigo - Situação vacinal e associação com a qualidade de vida, a funcionalidade e a motivação para o autocuidado em idosos (Santos et al., 2009).

Neste artigo é analisada a situação vacinal de idosos quanto às vacinas antiinfluenza, a dupla tipo adulto, e à antipneumocócica polissacarrídea 23 valente, relacionando-a com aspectos demográficos, com a qualidade de vida, o índice de funcionalidade e a motivação para o autocuidado. De forma geral, o estudo traz os inúmeros benefícios das vacinas aos idosos, uma vez que fornece elevada proteção contra as freqüentes complicações associadas à gripe, ao tétano e a pneumonia, as quais são responsáveis por internações e óbitos. Acredita-se, após o estudo, que o ato de adesão à vacinação demonstra uma motivação para o autocuidado, propiciando a prevenção de doenças e contribuindo para a manutenção da capacidade funcional e da qualidade de vida.

\section{Fonte: Scielo Brasil e Governo do Distrito Federal.}

Outros 3 artigos selecionados (Tabela 1) tratam da qualidade de vida para o idoso, porém não se relacionam a nenhum tópico específico do folder utilizado para comparação.

Em um dos estudos objetivou-se conhecer a opinião dos idosos sobre o que é qualidade de vida, por análise de conteúdo, tendo como resultado a existência de três grupos de idosos segundo sua definição de qualidade de vida: o primeiro valorizou a questão afetiva e a família; o segundo priorizou a obtenção do prazer e conforto; o terceiro poderia ser sintetizado como o idoso que identifica a qualidade de vida colocando em prática o seu ideário de vida. Em outro artigo, fez-se revisão na literatura, e mostraram-se considerações sobre a educação em saúde como agente promotor da qualidade de vida a fim de atingir ações e condições conducentes à saúde do idoso no contexto brasileiro. Com isso, o trabalho educacional tem como desafio a integração de conhecimentos dispersos das áreas humanas e biológicas aos saberes populares, pressupondo novas interfaces de atuação no modelo de assistência à saúde. A educação em saúde desponta como um elo entre os desejos e expectativas dessa população por uma vida melhor e as projeções e estimativas dos governantes ao oferecer programas de saúde mais eficientes. No último artigo, avaliou-se a satisfação de idosos em relação à sua qualidade de vida, tendo como resultados que a satisfação mostrou-se regular. As dimensões da qualidade de vida apontadas na escala de 
Flanagan foram: desenvolvimento pessoal e realização; relações com familiares; participação social; bem-estar físico e material; amizade e aprendizagem. 


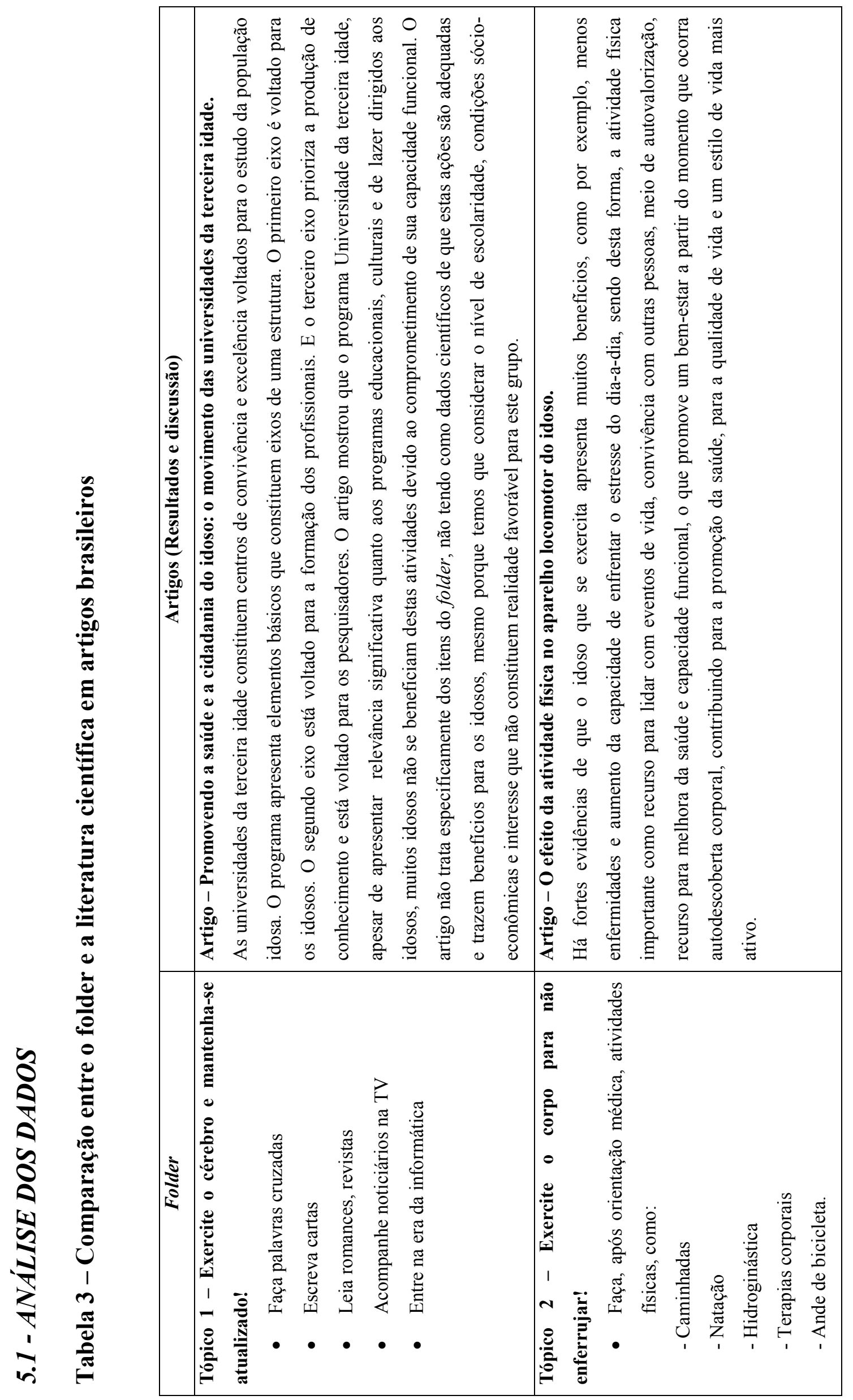




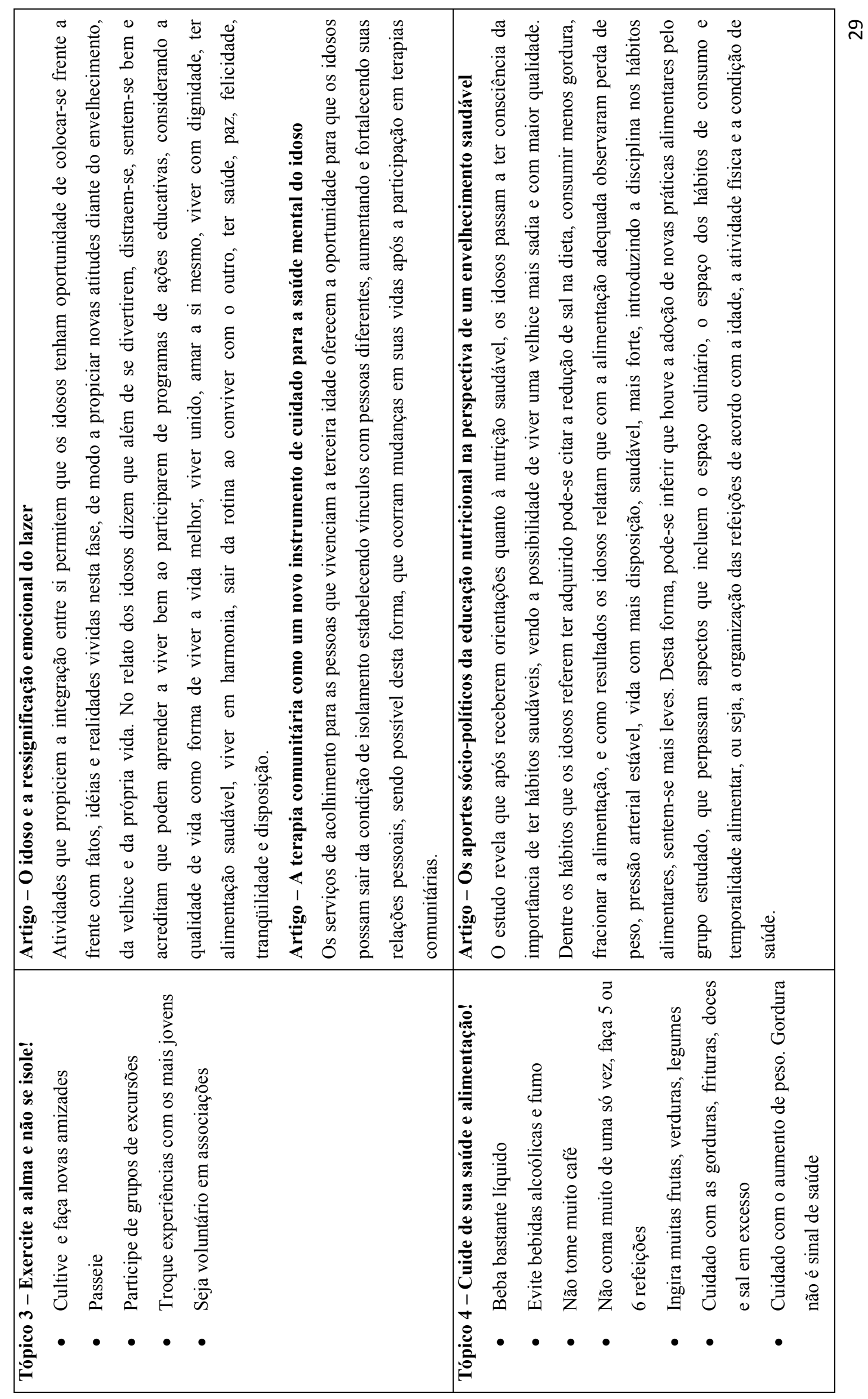




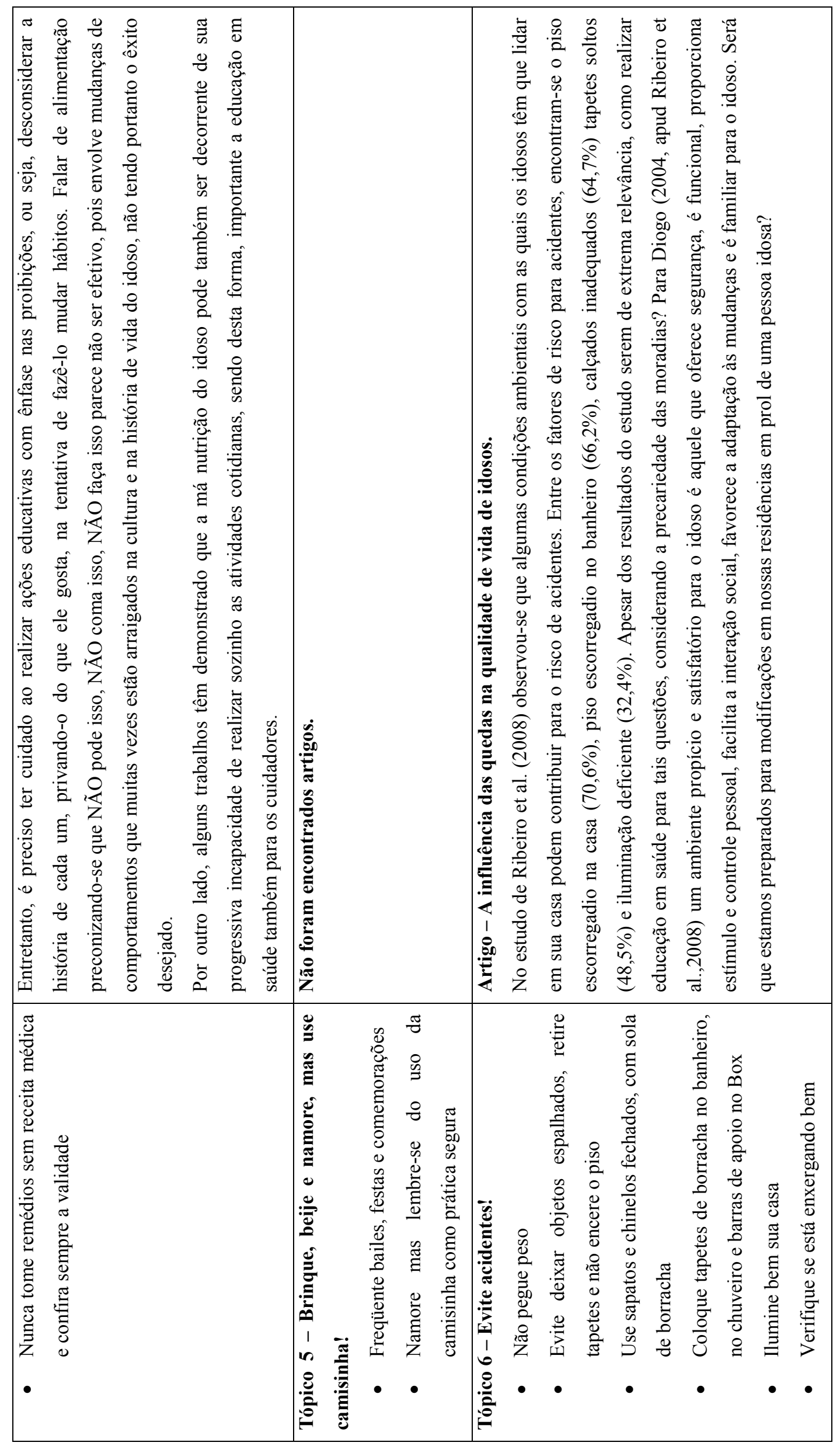



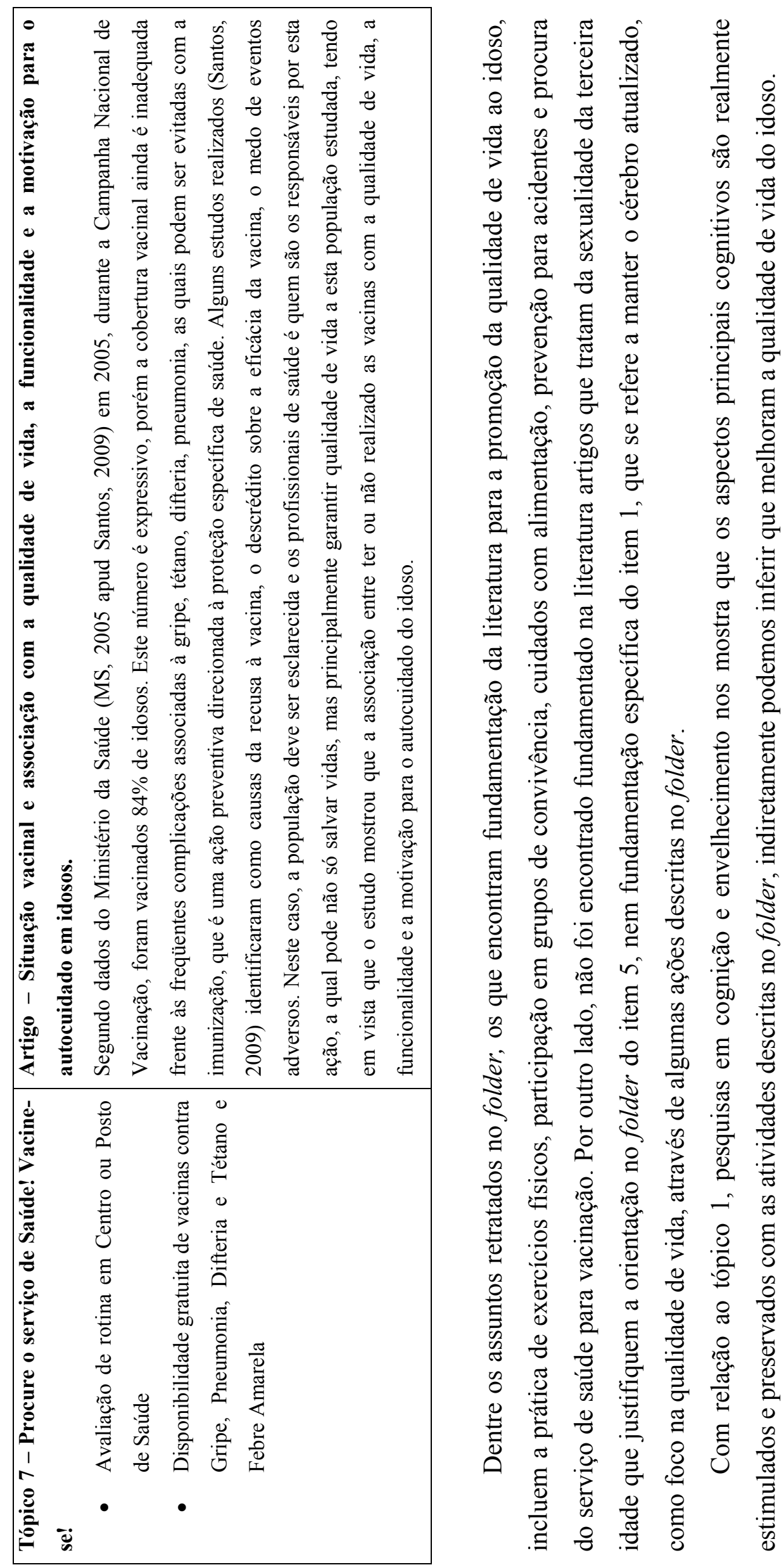


\section{DISCUSSÃO E CONSIDERAÇÕES FINAIS}

Quanto à promoção do envelhecimento saudável, ações que trabalhem a conscientização da sociedade e dos próprios idosos sobre hábitos de vida que minimizem os problemas naturais advindos do envelhecimento são de fundamental importância para a promoção da qualidade de vida.

De acordo com a revisão bibliográfica realizada, verifica-se que o folder utilizado para o desenvolvimento deste trabalho traz inúmeras informações pertinentes no que diz respeito à promoção e educação da saúde de idosos, a qual objetiva a qualidade de vida, o que pode ser confirmado pelos estudos científicos disponíveis.

Porém, sugerimos algumas adaptações na estrutura apresentada, no que se refere às mudanças de hábitos de vida que se deseja alcançar, principalmente, levando-se em conta o contexto histórico e cultural da vida dos idosos.

Dentre os aspectos que podem ser modificados no folder, visando um melhor aproveitamento das informações e adesão às propostas de ação educativas, é utilizar-se de menos textos e incluir mais figuras ilustrativas, uma vez que a grande maioria da nossa população-alvo, ou tem nível de escolaridade baixo, ou tem problemas de acuidade visual.

Outro aspecto interessante observado é que as ações direcionadas ao idoso no folder são escritas de forma imperativa, como uma ordem, não sendo adequadas para uma população que tem uma vida inteira repleta de experiências, costumes, cultura própria, crendices e hábitos arraigados.

Além disso, profissionais de saúde se veem cada vez mais desafiados a corresponder qualitativamente às demandas dos idosos, que com o aumento da longevidade, requer políticas de saúde voltadas à qualidade de vida através de programas voltados para esta população com ênfase na promoção e educação em saúde.

O material educativo utilizado para o estudo leva em conta que os relacionamentos interpessoais através de programas de vivências, boa saúde física e mental, lazer, educação, ambiente adequado, realização de atividades físicas, alimentação saudável, imunizações são extremamente importantes e condizentes com a literatura pesquisada.

Os resultados deste estudo não podem ser generalizados, devem ser contextualizados em cada comunidade, mas sugere-se que os itens elencados no folder, 
com suas devidas adaptações, são de extrema importância para o desenvolvimento da qualidade de vida para os idosos.

Ações educativas devem ser consideradas como investimentos na saúde pública, reduzindo as internações hospitalares e conseqüente sofrimento dessa parcela da sociedade, uma vez que propiciam qualidade de vida aos idosos. Entre os desafios a serem enfrentados, é preciso que haja melhora na divulgação das informações e uso de políticas voltadas para a saúde do idoso adequadas, que promovam a qualidade de vida.

Entretanto, para que este folder seja realmente efetivo no que se refere à promoção da saúde, é preciso que seja utilizado em ambientes propícios, os quais desenvolvam ações voltadas para a qualidade de vida do idoso. Não é suficiente a sua existência e distribuição, mas sim equipes multidisciplinares preparadas para lidar com um público-alvo tão específico, com demandas diversas, sendo de fundamental importância realizar-se busca ativa para trazer tais usuários ao serviço de saúde.

Enfim, o folder apesar de apresentar informações relevantes, não é tão atrativo, as informações são básicas, e sem o contexto fornecido pela equipe que atende, pode perder a eficiência. Outras pesquisas científicas podem ser realizadas para aprimorar o conhecimento acerca do assunto, entre elas :

- Estudar a opinião dos usuários sobre cada tópico do folder, relacionandoos com qualidade de vida desses e a ideal;

- Verificar a aplicabilidade dos tópicos do folder com os usuários e se houve mudanças de comportamentos frente às ações educativas transmitidas através do folder;

- Avaliar o conhecimento que as equipes de saúde tem sobre cada tópico na vida do idoso, e quais são as informações mais importantes para garantir qualidade de vida no envelhecimento;

- Aprofundar cada tópico com pesquisas de revisão e de opinião com públicos de idosos e pré-idosos, em diferentes situações (com demência ou sem demência, com bom nível sócio-econômico ou não, escolarizados ou não) e ver a correlação em cada grupo estudado;

- Comparar o impacto da informação em usuários de serviço público e de serviço particular de saúde;

- Verificar qual o melhor método de transmissão de informação para o público usuário de serviço público de saúde. 


\section{REFERÊNCIAS BIBLIOGRÁFICAS}

ALENCAR, MSS; BARROS JUNIOR, FO; CARVALHO, CMRG. Os aportes sóciopolíticos da educação nutricional na perspectiva de um envelhecimento saudável. Campinas - SP: Revista de Nutrição, volume 21, Julho/Agosto 2008.

CASTRO, Juracy Correa; BASTOS, Fernando Antonio Cunha; CRUZ, Thales Henrique Peres; GIANI, Tânia Santos; FERREIRA, Márcia de Assunção; DANTAS, Estélio Henrique Martins. Níveis de qualidade de vida em idosas ativas praticantes de dança, musculação e meditação. Rio de Janeiro- RJ: Revista Brasileira de Geriatria e Gerontologia, Volume 12, nº 2, 2009.

CONSELHO NACIONAL DE SAÚDE - CNS, disponível em www.conselho.saude.gov.br/docs/Resoluções/Reso196.doc, acessado em 31.01.10.

GÁSPARI, Jossett Campagna; SCHWARTZ, Gisele Maria. O idoso e a ressignificação emocional do lazer. Brasília-DF: Psicologia: Teoria e Pesquisa, Janeiro/Abril 2005.

GUIMARÃES, Iraci Gonçalves. Quando esquecer é o problema: Representações Sociais de familiares sobre saúde mental no envelhecimento e os desafios impostos pela demência. 2005. 193 f. Tese (Mestrado em Ciências da Saúde) - Faculdade de Ciências da Saúde - Universidade de Brasília, Brasília, 2005.

INSTITUTO BRASILEIRO DE GEOGRAFIA E ESTATÍSTICA - IBGE. Censo Demográfico. 2002. Disponível em: www.ibge.gov.br. Acesso: 22/01/10.

MELO, Mônica Cristina de; SOUZA, André Luiz; LEANDRO, Edélvio Leonardo; MAURICIO, Herika de Arruda; SILVA, Iedo Donato; OLIVEIRA, Juliana Maria Oriá de. A educação em saúde como agente promotor de qualidade de vida para o idoso. Rio de Janeiro - RJ: Revista Ciência \& Saúde Coletiva, volume 14, setembro/outubro.2009.

MINISTÉRIO DA SAÚDE, As Cartas da Promoção da Saúde, 2002, disponível em www.bvsms.saude.gov.br/bvs/publicacoes/cartas_promocao.pdf, acessado em 03/02/10. 
ORGANIZAÇÃO MUNDIAL DE SAÚDE - OMS. Relatório Mundial de Saúde - The world health report 2001 - Mental health: New understanding, new hope. Disponível em: www.who.int/whr/. Acesso em 14/01/10.

PEDRINELLI, André; Garcez-Leme, L.E; NOBRE, R.S.A. O efeito da atividade física no aparelho locomotor do idoso. São Paulo: Revista Brasileira de Ortopedia, volume 44, Março/Abril 2009.

RIBEIRO, AP; SOUZA, ER; ATIE, Soraya; SOUZA, AC; SCHILITHZ, AO. $A$ influência das quedas na qualidade de vida de idosos. Rio de Janeiro: Ciência \& Saúde Coletiva, volume 13, Julho/Agosto 2008.

RODRIGUES, Humberto Gabriel; AVERSI-FERREIRA, Tales Alexandre; PAIVA, Luice Rezende. Efeitos do Envelhecimento sobre o encéfalo. Passo Fundo: Revista Brasileira de Ciência do Envelhecimento Humano, Volume 5, $\mathrm{n}^{\mathrm{o}}$ 2, Julho/Dezembro/2008.

ROCHA, IA; BRAGA, LAV; TAVARES, LM; ANDRADE, FB; FERREIRA FILHA, MO; DIAS, MD; SILVA, AO. A terapia comunitária como um novo instrumento de cuidado para saúde mental do idoso. Brasília-DF: Revista Brasileira de Enfermagem, volume 62, Setembro/Outubro 2009.

SANTOS, BRL; CREUTZBERG, Marion; CARDOSO, R.F.M.L; LIMA, S.F; GUSTAVO, A.S; VIEGAS, Karin; WELFER, Márcia; SOUZA, A.C.A. Situação vacinal e associação com a qualidade de vida, a funcionalidade e a motivação para o autocuidado em idosos. São Paulo - SP: Revista Brasileira de Epidemiologia, volume 12, Dezembro, 2009.

SANTOS, SR, Santos IBC, Fernandes MGM, Henriques MERM. Qualidade de vida do idoso na comunidade: aplicação da Escala de Flanagan. Revista Latino-Americana de Enfermagem 2002; 10(6): 757-64. 
SOUSA, Liliana; GALANTE, Helena; FIGUEIREDO, Daniela. Qualidade de Vida e bem-estar dos idosos: um estudo exploratório na população portuguesa. São Paulo: Revista de Saúde Pública, Volume 37, nº 3, Junho/2003.

TAVARES, D.M.S et al. Incapacidade Funcional entre idosos residentes em um município do interior de Minas Gerais. Florianópolis - SC: Revista Texto \&Contexto Enfermagem, volume 16, nº 1, p. 32-39, jan/mar. 2007.

VECCHIA, Roberta Dalla; RUIZ, Tânia; BOCCHI, Silvia Cristina Mangini; CORRENTE, José Eduardo. Qualidade de Vida na terceira idade: um conceito subjetivo. São Paulo: Revista Brasileira de Epidemiologia, 2005; 8(3): 246-52.

VERAS, Renato Peixoto; CALDAS, Célia Pereira. Promovendo a saúde e a cidadania do idoso: o movimento das universidades da terceira idade. Rio de Janeiro-RJ: Ciência \& Saúde Coletiva, volume 9, Abril/Junho 2004. 
ANEXO 


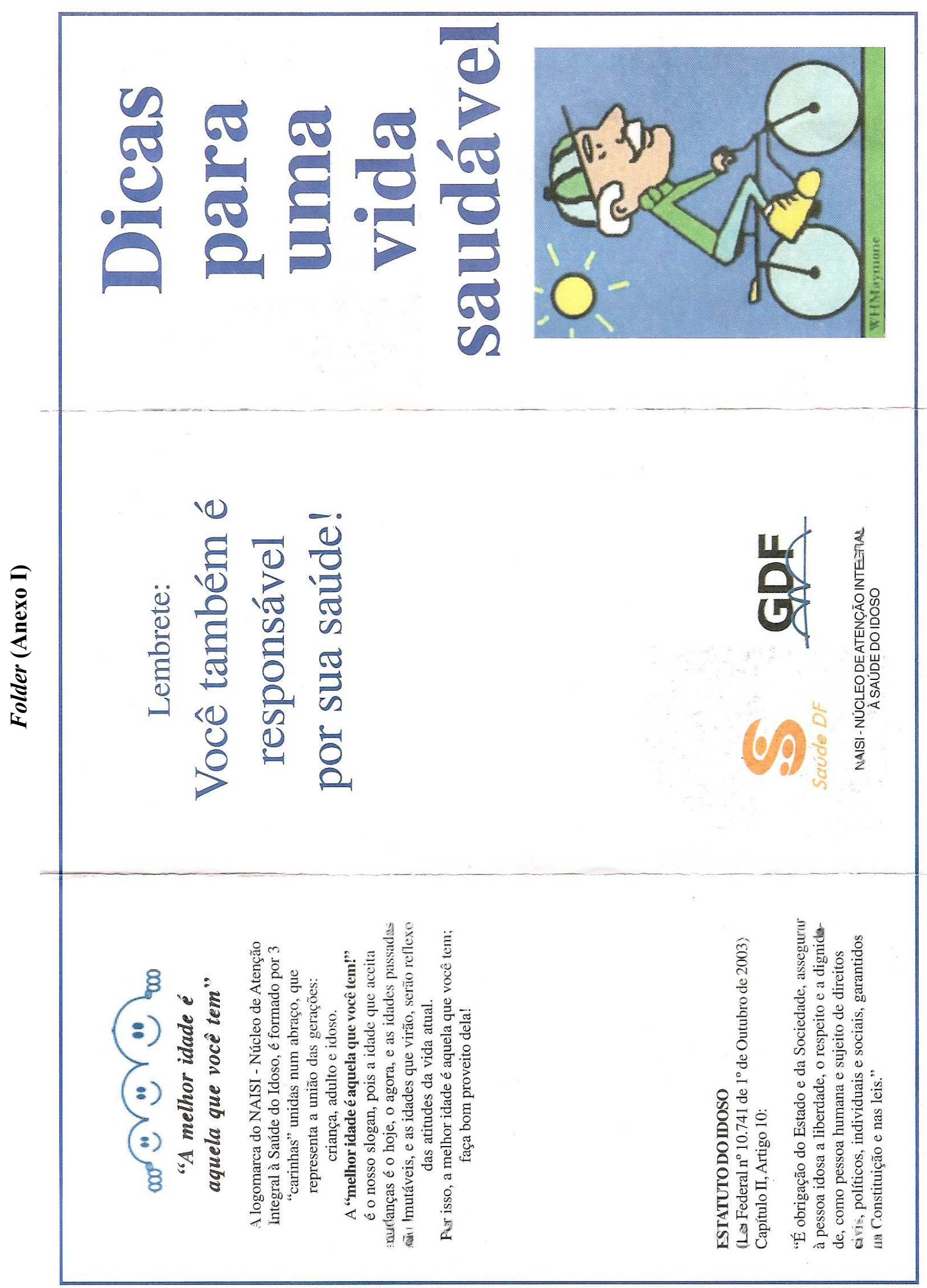



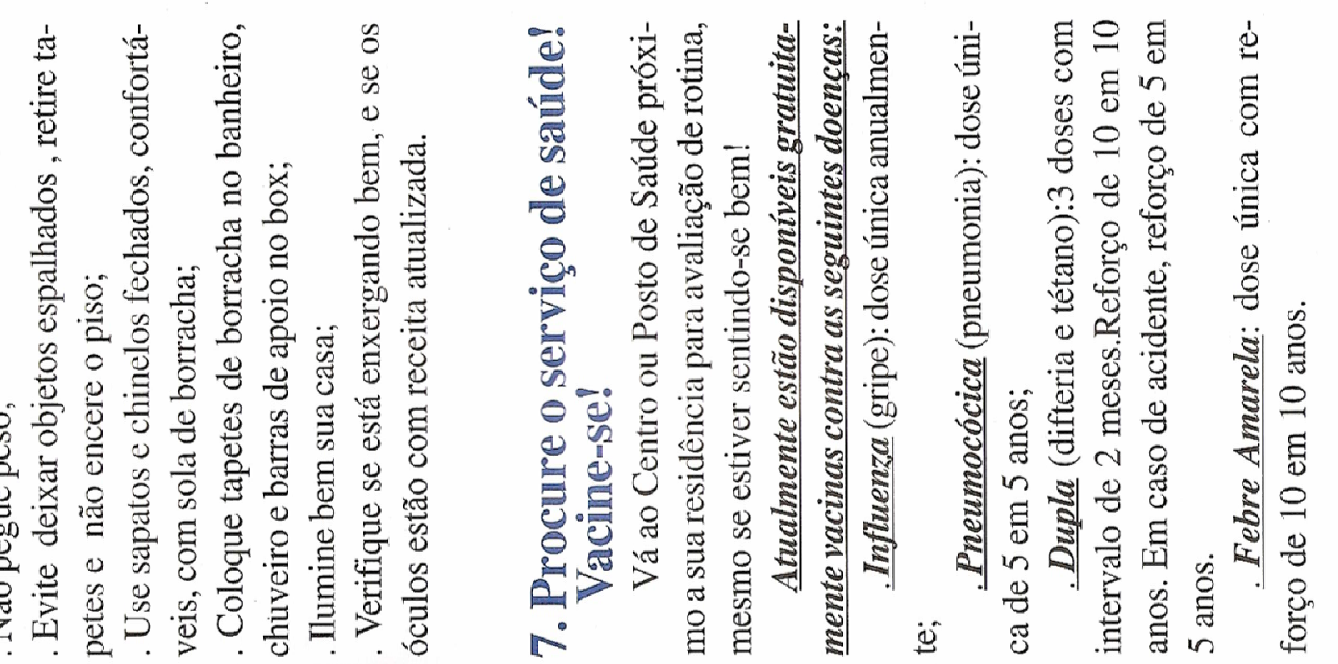

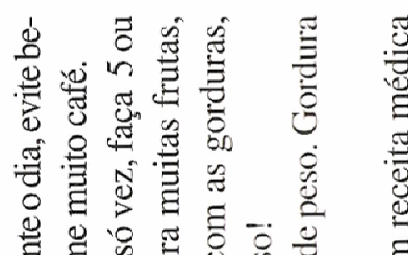

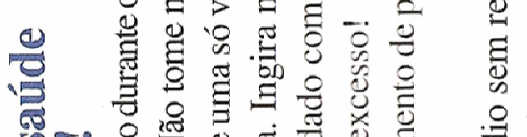

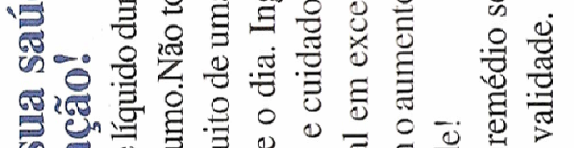

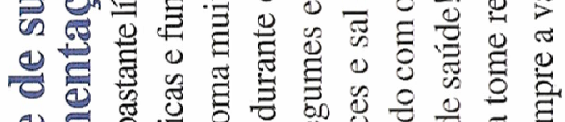

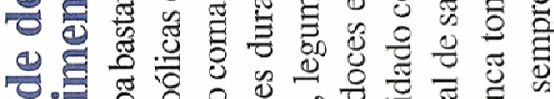

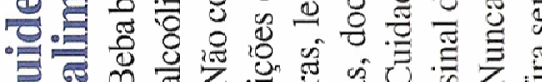

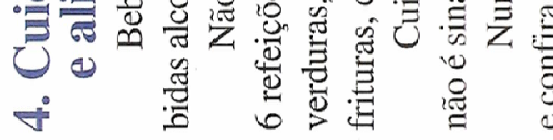

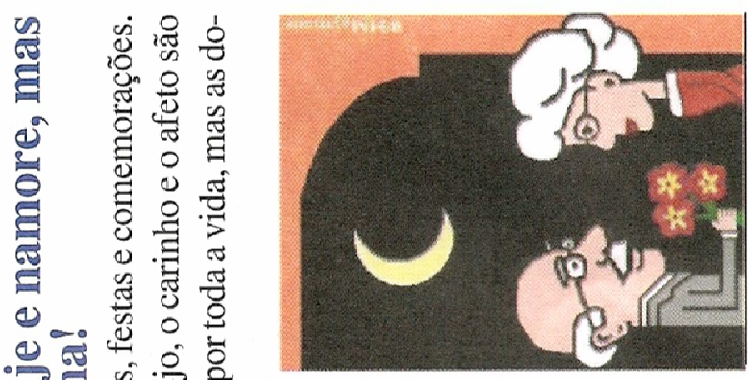

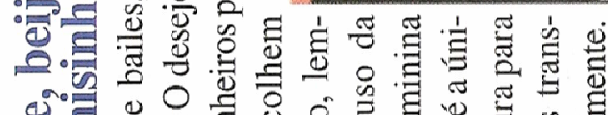

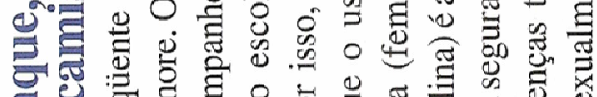

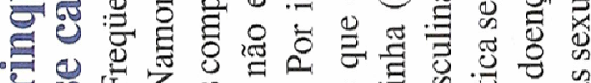

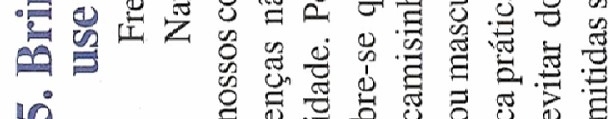

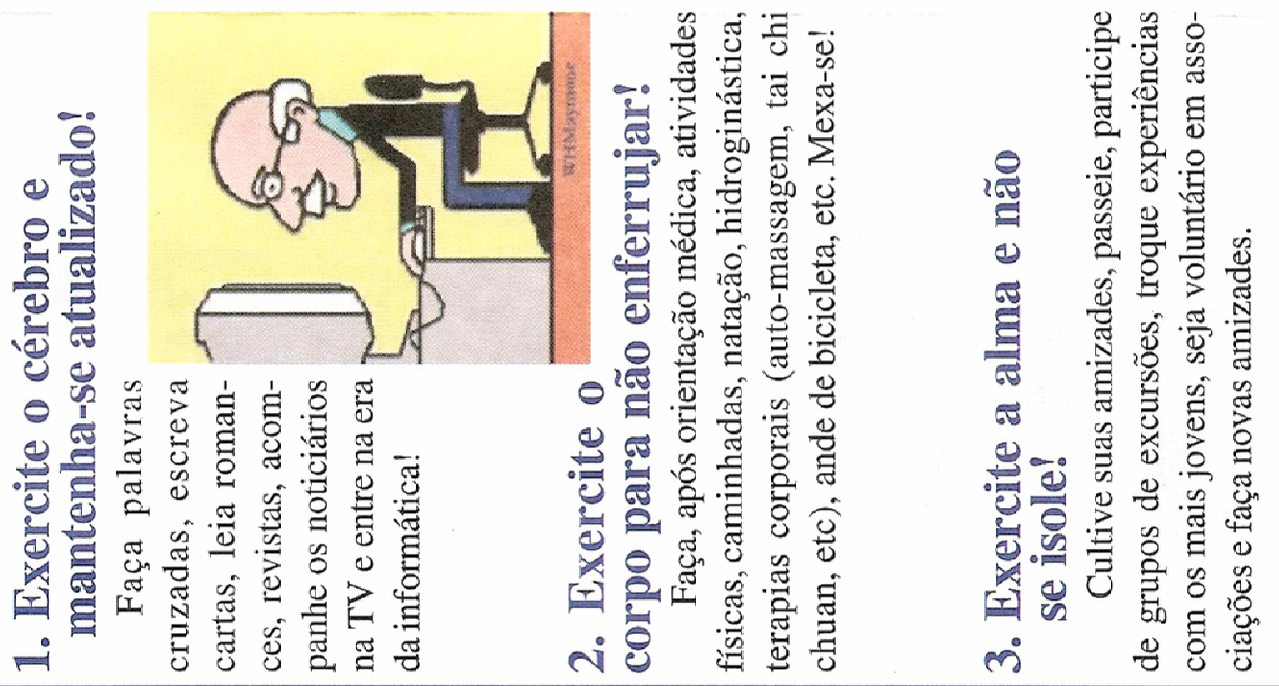

